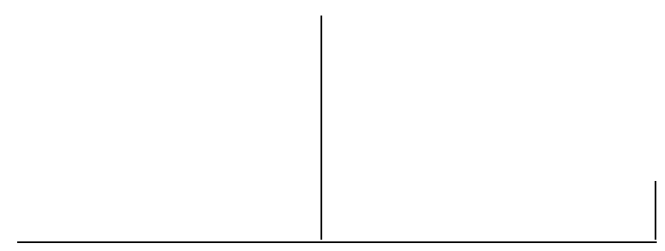

Rev. Latinoam. Psicopat. Fund., VII, 1, 9-19

\title{
Tornar-se uma outra na histeria e ser uma outra do falso self*
}

Teresa Pinheiro

Este trabalho pretende fazer uma comparação entre a histeria e o falso self a partir do projeto de "ser uma outra" presente nas duas patologias. O projeto de "tornar-se uma outra" na histeria aponta para personagens que necessariamente estão presentes nesse modelo fantasmático: a vítima e o vilão. A noção de "ser uma outra", no falso-self, apresenta-se como única forma possível de estar no mundo, onde a ilusão não tem lugar.

Palavras-chave: Histeria, falso-self, fantasia, ilusão, melancolia

* Trabalho apresentado no VI Congresso Brasileiro de Psicopatologia Fundamental, Recife, 2002. 
Este artigo é uma versão mais aprofundada do trabalho apresentado no VI Congresso de Psicopatologia Fundamental, realizado em Recife em 2002. Trata-se de um dos aspectos trabalhados na pesquisa "Comparação clínica e metapsicológica entre pacientes melancólicos e portadores de Lúpus Eritematoso Sistêmico" que é realizada com base no acordo do PPTP, IPUB e HU. Esta investigação decorre da interrogação sobre os impasses da clínica diante das chamadas novas forma de sofrimento psíquico. Nas duas últimas décadas, temos nos deparado com um número cada vez maior de casos de depressão, somatizações, anorexia, bulimia e fobias, além dos casos de dependência química. Esses pacientes chegam aos consultórios ou às instituições levados por uma enorme angústia, cuja causa desconhecem, ou apresentando um quadro clínico de forte depressão.

Sem lembrar de sonhos, sem fazer lapsos, parecem incapazes de atender à regra básica da psicanálise, a da associação livre. Apesar de se referirem muito ao próprio corpo, falam dele como se fosse de um estranho. São rigorosos em seus valores morais, desdenham as ilusões neuróticas, não se projetam no futuro e falam com um discurso parnasiano. Todos estes aspectos nos remeteu a repensar a metapsicologia da melancolia e a teoria do trauma em Ferenczi.

Nos últimos dez anos, temos trabalhado os argumentos principais apresentados por Freud na metapsicologia da melancolia: ambivalência, a diferença entre o luto e a melancolia diante da perda do objeto, a clivagem, o superego cruel, a identificação narcísica, a vergonha, o modo de produção fantasmática e a forma discursiva do melancólico tais como encontramos nos textos freudianos e também as noções que estão presentes na teoria do trauma ferencziano - identificação com o agressor, introjeção, confusão de línguas, desmentido e as descrições clínicas deste autor sobre o que ele chamava de casos difíceis. Esse trabalho teórico foi sempre confrontado com a clínica e nos permitiu ampliar o leque nosográfico da melancolia (cf. Pinheiro, 1995, 1995a, 1997, 1997a, 1998, 2000, 2001, 2002). Procuramos retirar da melancolia o caráter com que geralmente é descrita e pensada - como ausência ou negativa com relação aos parâmetros do modelo da histeria. Pudemos identificar um modelo de subjetivação próprio da melancolia bastante diferente daquele que estamos acostumados a trabalhar na psicanálise 


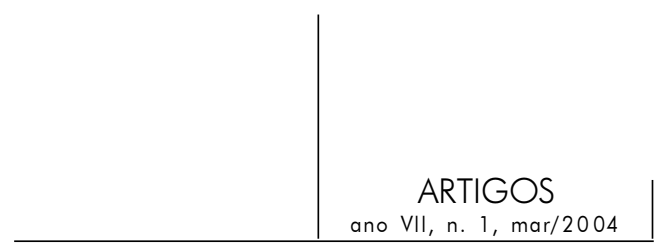

por meio do modelo da histeria. Assim nos afastamos das descrições do melancólico como: o que não fantasia, esvaziado; o que não soube fazer um luto; o que parece psicótico, mas que só fala de castração; o que parece as vezes neurótico, mas que não é... Procuramos mostrar como ambivalência, ambigüidade, verdade, castração, ideal do Eu e crueldade superegóica são parâmetros para a compreensão do aparelho psíquico, que fazem todo sentido na histeria e que serviram de balizadores para a compreensão das neuroses, das perversões e das psicoses, tais como a esquizofrenia e a paranóia, mas que não dão conta da melancolia e das patologias descritas pelos americanos como sendo personalidades narcísicas, denominadas por Winnicott de falso self, e por grande parte dos psicanalistas de casos limites e que na clínica contemporânea vem se apresentando em número cada vez maior.

Há cerca de dois anos, entramos em contato com uma equipe que realiza grupos Balint em dois hospitais públicos de Recife. Essa equipe trabalha com pacientes com Lúpus e sua investigação indicou uma aproximação possível entre o que os pacientes apresentavam como sintomas psicológicos e o que descrevíamos nos nossos trabalhos. A partir de então uma parte da pesquisa foi sendo realizada por essa equipe em Recife, enquanto no Rio de Janeiro, em uma outra parte da pesquisa nos propusemos fazer um estudo comparativo com atendimento no IPUB de pacientes com Lúpus e pacientes deprimidos.

Em virtude desses antecedentes, no presente artigo, usaremos o termo melancolia não só para nos referirmos ao quadro clássico da melancolia, mas também quando nos remetemos às figuras nosológicas dos ditos casos limites, os falsos-selves, as personalidades narcísicas, os somatizadores, distímicos, bulímicos, anoréxicos e dependentes químicos.

Muito já se disse do quanto a melancolia se parece com uma neurose - mais especificamente com a histeria. Também há uma tendência a aproximar a melancolia da psicose. Para nós, tanto uma quanto outra tendência se apóia em falsas premissas. Na verdade, consideramos que hoje nos vemos diante da necessidade de problematizar o modelo da histeria, visto que estamos nos deparando, na atualidade, com quadros que este modelo parece ser insuficiente para explicar, não só em relação às dificuldades que vêm colocando no âmbito da clínica, como também no âmbito de uma maior precisão conceitual.

Ao contrário da clínica da neurose, em que a ilusão é o tecido sobre o qual trabalhamos, a clínica da melancolia parece nos remeter sempre para o insuportável da castração. Nossa proposta aqui é tomar o diferencial entre a histeria e as patologias que obedecem ao registro metapsicológico da melancolia, no que se refere à dimensão ilusória do projeto de "ser uma outra", visando contribuir para que se estabeleça uma distinção mais nítida entre estes modelos. 


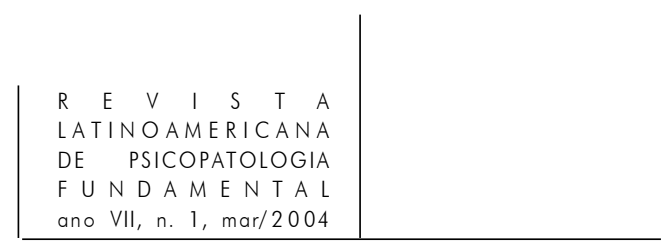

Encontramos na histeria, entre outros projetos, o projeto de "tornar-se uma outra". "Ser uma outra", nesse caso, é estar em outro lugar, idealizar o príncipe encantado, viver no mundo que sempre parece tão perfeito dos salões da corte. $\mathrm{Na}$ histeria, o bordado fantasmático parece, na maior parte das vezes, excessivo, barroco demais, tem muita renda, muito ponto festonê, muito crivo. É assim que aparece para Dora o mundo maravilhoso de Mme K., assim é também o mundo sonhado por Mme Bovary. ${ }^{1}$ O projeto de ser uma outra é, nesses casos, muito elaborado e cultivado com carinho. A vida só parece ser possível se a ilusão ganhar todas as cores. Os filmes de Doris Day parecem ter sido feitos para as mulheres sonharem que a felicidade é um estado eterno e de preferência "cantante". É claro que antes disto elas têm de passar por muito sofrimento, tem que acontecer muito desencontro, mas passado o susto, tudo acaba bem.

Hollywood vendeu durante anos o bordão de que: para as mulheres serem felizes, bastava estarem no lugar certo, na hora certa, com o homem certo. O modelo serve até hoje para qualquer novela ou seriado de sucesso.

A fantasia de "ser uma outra" está exemplificada na obra freudiana de várias maneiras, uma delas é essa:

Depois que chamei a atenção de uma das minhas pacientes para suas fantasias, ela me contou ter-se surpreendido em lágrimas na rua e, ao refletir no mesmo instante sobre o motivo deste pranto, ter conseguido capturar a fantasia que se segue. Em sua imaginação, ligara-se amorosamente a um conhecido pianista de sua cidade (embora não o conhecesse pessoalmente); em seguida fora abandonada, com o filho que tivera com ele (na verdade não tinha filhos), ficando na miséria. Fora nesse momento de sua fantasia que irrompera em lágrimas. (Freud, 1908, v. IX, p. 142)

Neste texto, como vemos, a fantasia histérica apresenta todos os ingredientes necessários de como é "tornar-se uma outra". "Ser uma outra" neste caso é ser a escolhida pelo grande pianista, que ela nem conhecia, mas no bordado fantasmático está implícito que ele certamente conhecia outras mulheres. E este dado, na histeria, é de importância fundamental. Na seqüência da produção fantasmática, ele apaixona-se por ela e a faz, neste instante, tornar-se uma outra: torna-se aquela com quem o pianista, que ela nem conhece, se liga amorosamente. Dentre todas as mulheres é ela a escolhida, e isso por si só já faz dela uma outra muito especial. Na seqüência da cena, o pianista surge como sendo, na verdade, um vilão terrível, um falso príncipe encantado - assim como todos os homens, ou como todas as outras pessoas, no sintoma histérico - que abandona a mulher grávida sem ter nenhuma consideração por ela. Temos, portanto, um vilão e uma

1. Ver a análise feita por Maria Rita Kehl, em Deslocamentos do feminino. 


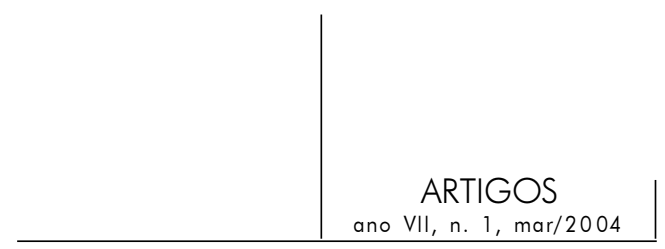

vítima, personagens cujas identidades de mau e boazinha ninguém pode pôr em dúvida. A vítima é vítima porque é ingênua. Não podia imaginar que o vilão fosse tão mau, logo ele que parecia tão bom e a quem todos admiravam. Ela é a moça ingênua, quase criança, fácil de ser enganada pelos homens. A seqüência da cena pode ser dedutível pela construção histérica: ele a abandona certamente por outra mulher. O triângulo amoroso está formado e a disputa dela, por um homem, será sempre com uma outra mulher.

Um outro exemplo é dado por Freud em "Psicologia de grupo e análise do ego":

Suponha-se, por exemplo, que uma das moças de um internato receba de alguém de quem está secretamente enamorada uma carta que lhe desperta ciúmes e que a ela reaja por uma crise de histeria. Então, algumas de suas amigas que são conhecedoras do assunto pegarão a crise, por assim dizer, através de uma infecção mental. O mecanismo é o da identificação baseada na possibilidade ou desejo de colocar-se na mesma situação. As outras moças também gostariam de ter um caso amoroso secreto e, sob a influência do sentimento de culpa, aceitam também o sofrimento envolvido nele. (Freud, 1921, v. XVIII, p. 101)

Ser uma outra envolve sempre algum sofrimento, ou melhor, a estética histérica de ser uma outra pressupõe uma mulher que sofre. O sofrimento, aí, é o adereço estético imprescindível. O belo do feminino é apresentado como sendo o sofrer por um homem. Assim se faz o laço identificatório das meninas do internato. Experimentar o sofrimento de uma outra mulher é como tomar posse do saber sobre o que é ser mulher. Os enredos se fazem todos na mesma maneira: um homem cobiçado, uma mulher ingênua e sofredora, um vilão e uma vítima. A felicidade está sempre em outro lugar, numa outra festa, em outra cidade, outra família, com outro marido e assim vai... O bordão poderia ser, sem problemas, esse: "Há em algum lugar do planeta uma mulher mais feliz que eu e ser esta mulher é ter tudo, é ter toda a felicidade do mundo!" Há um detalhe fundamental nesta postulação. Esse bordão é algo que a histérica sabe que pode ser falso, que está ali só alinhavando um tecido imaginário que ela considera imprescindível para viver, ele dá a ela o sonho de um dia banir todo o sofrimento e ao mesmo tempo garante, no presente, a estética da mulher que sofre por não ter aquilo que ela imagina que uma outra mulher pode ter.

O conceito de fantasia, dentre todos os conceitos freudianos, talvez seja o que reúne melhor e de forma mais sintética a aliança entre o eixo da linguagem e o da ordem da sexualidade. Quando Freud anuncia a Fliess que abandonou a sua neurótica (Freud e Fliess, 1887-1904, p. 265) e que pode conceber esse psiquismo como sendo constituído de representações, neste momento, ele passa a dar à representação autonomia, vôo próprio, concebendo-a como desvinculada 


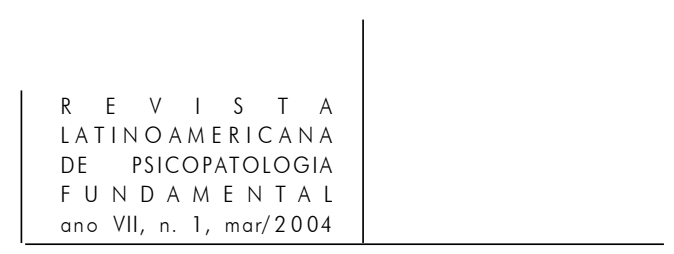

de um referente. Não importa se elas são fruto da percepção ou de construção fantasmática, para a realidade psíquica terão o mesmo valor. Se com esta afirmativa a teoria da sedução, que sustentava a etiologia da histeria (Freud, p. 185-218) se torna irrelevante, a fantasia, entretanto, passa a ganhar uma abrangência nunca antes pensada. Freud nos diz em 1914: "Se os pacientes histéricos remontam seus sintomas a traumas que são fictícios, então o fato novo que surge é precisamente que eles criam tais cenas na fantasia, e essa realidade psíquica precisa ser levada em conta ao lado da realidade prática" (Freud, 1914, v. XIV, p. 17).

A composição da fantasia histérica comporta sempre mais de um personagem e seu objetivo é ter a ilusão de que é possível ter acesso à subjetividade de todos os integrantes da cena fantasmática, ou seja, o que move o projeto da fantasia histérica é a ilusão, nesta montagem, de conhecer o desejo e aquilo que provoca o desejo, em cada um dos personagens. O elemento mágico da fantasia histérica antecipa todas as surpresas, todos os desejos são imaginados, todos os desencontros humanos apresentados e apreendidos. O que importa é colocar-se no lugar do outro para saber o que o outro quer, sente ou pensa. Tratase de sentir e imaginar todos os paradoxos que os sentimentos e as emoções humanas produzem. Neste sentido, o pré-requisito da dinâmica do aparelho psíquico reside na forma como foi concebido por Freud, qual seja, como um aparelho capaz de interpretar o objeto atribuindo-lhe uma subjetividade semelhante à sua própria. Não há, portanto, possibilidade de entender este aparelho de linguagem sem pensá-lo como um aparelho de interpretação. Em outras palavras, não se pode pensar o aparelho psíquico sem lançar mão do modelo da fantasia histérica. Desta forma, as propriedades de articulação da subjetividade como intérprete de outras subjetividades têm por pré-requisito o instrumental da fantasia.

Sem pretender esgotar a riqueza dessas formulações, podemos dizer, em linhas gerais, que é deste modo que se apresenta o modelo da histeria, modelo que forneceu as bases da primeira tópica freudiana, permitindo-lhe descrever, metapsicologicamente, o funcionamento psíquico.

Em 1919, no texto "Bate-se em uma criança", Freud propõe desmembrar a fantasia em três momentos. No primeiro momento, a fantasia seria de que o meu pai está batendo em outra criança por que me ama. No segundo momento, o meu pai está me batendo. Se tomarmos esses dois momentos da fantasia, temos a possibilidade de imaginar o que antecede as cenas e um depois das cenas, tanto no primeiro quanto no segundo momento. As cenas têm movimento. $\mathrm{O}$ enredo que se depreende delas está claramente vinculado à trama edipiana, os personagens são sujeitos que pertencem ao universo de quem elabora a fantasia. $\mathrm{O}$ cenário pode ser rico de detalhes, não há dúvida do tecido imaginário que constrói a paisagem 


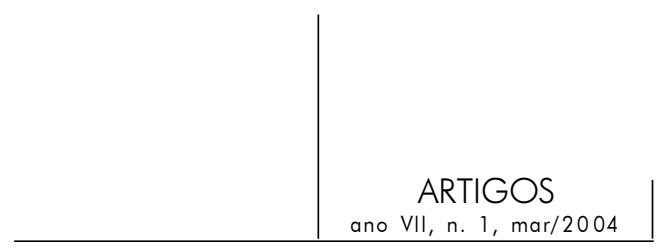

em questão. Já no terceiro momento, tudo parece bem diferente. Se não o tomássemos como sendo a síntese dos dois momentos anteriores, como Freud propõe, mas como se ele fosse único, talvez aí encontrássemos algo bem próximo do modelo fantasmático da melancolia. Nossa proposta (Pinheiro, 1997a, p. 41-4; 2002, p. 167-76) é tomarmos esse terceiro momento isoladamente. Neste caso, ele nada teria a ver com a fantasia histérica. O que está em questão aí não é interpretar o desejo dos personagens, não há tampouco nenhum movimento, não há uma causa que antecede a cena e nenhuma ação futura que se possa deduzir. A imagem é fixa, quase parada. A indeterminação dos personagens e a fixidez da imagem diferem totalmente da fantasia histérica, na qual uma elaboração está em curso e uma identificação será o resultado. Se tomarmos esse terceiro momento como o modelo fantasmático da melancolia, encontraremos nele todos os ingredientes que estão presentes na metapsicologia da melancolia e que nos trazem tantas questões na clínica com esses pacientes.

Tendo presente esta descrição, cabe nos determos, agora, no que se denomina como melancolia. $\mathrm{O}$ trabalho de pesquisa com pacientes que chamamos de melancólicos inclui uma gama de sintomas que vão desde as descrições da escola americana, que postulou as ditas personalidades narcísicas, até os pacientes traumatizados descritos por Ferenczi, o falso-self concebido por Winnicott, além da apropriação que a psicanálise fez da nosologia psiquiátrica dos borderlines, dos ditos casos limites, dos melancólicos e somatizadores. No andamento da pesquisa, fomos obrigados a trabalhar o conceito de fantasia em Freud, nos diferentes aspectos. Ao privilegiar aqui o projeto de ser uma outra para estabelecer uma distinção entre o modelo histérico e o modelo da melancolia, vamos, sobretudo, nos calcar no atendimento com pacientes com Lúpus, que na sua grande maioria parecem apresentar a descrição que Winnicott faz de falso self.

Ser uma outra no falso self, ou em qualquer patologia que obedeça à gramática da melancolia, é bem diferente do projeto de ser uma outra da histeria. Ser uma outra não é um projeto com os bordados da histeria, é a única forma de ser que se apresentou como possível.

Acreditamos que a proposta da teoria do trauma em Ferenczi, postulada para dar conta do que ele chamava de casos difíceis, é bastante próxima do paciente "falso-self" apresentado por Winnicott. A noção de progressão traumática da qual Ferenczi fala seria uma invenção de um "Eu" antes que o Eu tivesse condições de advir. Neste sentido, como M. Torok (Abraham e Torok, 1995), acreditamos que é perfeitamente possível aproximar a identificação com o agressor em Ferenczi e a sombra do objeto que caiu sobre o Eu em Freud. A explicação sobre a identificação com o agressor a partir do conceito de incorporação dá, inclusive, melhor inteligibilidade à noção de "a sombra do objeto caiu sobre o Eu". Ainda 


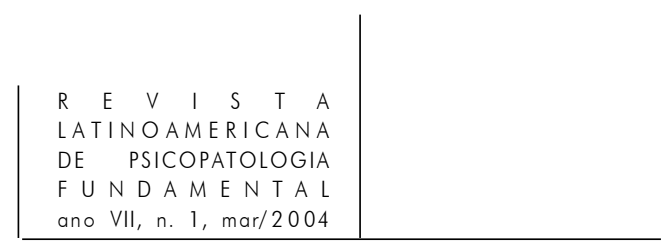

no mesmo sentido, podemos tomar o falso-self patológico de Winnicott, figura nosológica quase idêntica ao traumatizado ferencziano, como equivalente à identificação com o agressor e à sombra do objeto. Essas aproximações são possíveis pela equivalência, entre esses autores, da descrição que fazem da clivagem nesses casos e, como conseqüência, da artificialidade do EU nesses pacientes. Forjar-se um Eu é, nesse sentido, uma saída possível diante de uma situação limite para a criança. Inventa-se um Eu com base em uma apropriação mimética do objeto, a identificação narcísica é aqui não uma primeira identificação e que mais tarde será o núcleo das instâncias ideais, como Freud afirmou em 1923. Ela é a única possível e não dará lugar a um Eu que seja um precipitado de identificações como encontramos na neurose. Ser uma outra é a única forma de ser, pois o si-mesmo parece ser justamente o que foi perdido.

Há, sem dúvida, um projeto estético envolvido nesse modo de ser melancólico. Essa outra que se forja é alguém que quer ser reconhecido como sendo corajoso ao encarar a própria condição humana, é alguém que não se ilude com bobagens como os neuróticos, é alguém que pretende dominar de forma unívoca os conceitos de sinceridade e justiça. Mas o que nos interessa aqui é o que vem a ser esse "ser uma outra" do falso self. O sentimento de estranheza parece ditar a questão. Como se ser o "ser si mesmo" fosse uma abstração, algo perdido pelo caminho e do qual elas não têm mais lembrança alguma.

Ferenczi fala, na sua teoria do trauma, que no momento do desmentido o traumatizado perde a certeza de si, não confia mais na sua própria percepção do mundo e dos seus sentimentos (cf. Pinheiro et al., 1998, p. 160-75). Essa hipótese pode nos ajudar a entender porque o discurso melancólico é tão cheio de certezas, não parece permeado pela dúvida e é tão asséptico nos seus sentimentos. Como se o modelo defensivo de "ser uma outra" fosse "ser a outra da certeza de si", que jamais foi assaltada pela dúvida. Ser uma outra é ter uma carapaça, algo que a distancia do sentimento de si e que forneceu todos os instrumentos para sobreviver neste mundo. $\mathrm{O}$ conceito de clivagem na teoria do trauma ferencziano enriquece de alguma maneira a postulação de falso-self de Winnicott (cf. Verztman, 2002, p. 59-78). Uma das coisas que mais saltam aos olhos no trabalho com essas pacientes é a sensação de que procuraram se equipar como puderam para "sobreviver". O viver é um luxo neurótico. Ao nos depararmos com esses pacientes nos damos conta do quanto o instrumental da ilusão, instrumental que parece não estar disponível para esses pacientes, serve confortavelmente aos neuróticos. O que está em falta na melancolia é, entre outras coisas, o conforto. Conforto que a ilusão proporciona ao neurótico que, diante da inevitável aceitação da castração, a coloca entre aspas, como transitória, circunstancial, ao lançar mão das instâncias ideais que garantirão, graças à ilusão, uma construção imaginária de que o passado foi vivido longe dela (castração) e no futuro ela será banida, essa 


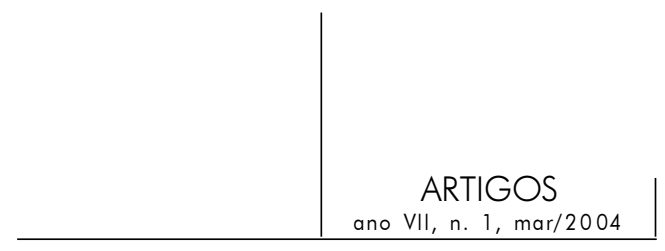

é pelo menos a promessa do ideal do Eu. Em contrapartida, a vida do melancólico é o aqui e agora. Não há para trás nenhuma figura de "Sua Majestade, o bebê", do passado pouco se lembram e o que se lembram são imagens soltas que não fazem elo, não constroem uma versão da história de si. O futuro é de novo uma imagem parada, fixa, sem possibilidade de troca. Está longe de ser uma tela branca na qual se pode projetar e projetar-se no futuro, o que implicaria que esse futuro seria passível de ser mudado, modulado com o passar do tempo. Na maior parte das vezes, projetar-se no futuro parece ser o inimaginável, pois para projetar-se no futuro é imprescindível que se tenha ilusão, é preciso ter familiaridade com o mundo dos sonhos, sair da concretude do aqui e agora.

O mundo melancólico é parnasiano, as imagens são descritas minuciosamente para que não paire qualquer dúvida ou ambigüidade. O ser uma outra não está ali para forjar a realização do desejo, mas para anestesiar, impedir as surpresas e sobressaltos. Resta ao sofrimento ter como destino de expressão o próprio corpo. Se parecem indiferentes ao falar dos seus sentimentos, no corpo o sofrimento tem concretude feito as palavras que usam. Não há entrelinhas nesse sofrimento, ou ambigüidades. As articulações doem ou a pele apresenta manchas, texturas diferentes, ou, ainda, o cabelo cai. O corpo, com sua base material palpável, parece ser o único reduto encontrado para uma história poder ser contada.

Poderíamos pensar que a questão da vitimização que aparece no discurso das melancolias apontasse para a mesma questão do lugar de vítima da histeria. Mas na melancolia isto não faz par com o vilão. Não há vilões. Não há também nenhuma intenção de, na relação transferencial, fazer do analista um mero espectador e comprovador de que há sempre um vilão e que o paciente, por sua vez, é a grande vítima. Se o analista é colocado como espectador no trabalho com as melancólicas é para que, nesta posição, ele possa vê-la, atestar sua existência como outra e, quem sabe, ser testemunha de um si mesma que foi ali para enfim advir. O analista é chamado a testemunhar que ela ali faz presença, é chamado para com seu olhar fazer o contorno da imagem corporal da paciente, ajudandoa assim a manter uma imagem de si que parece sempre ser tão tênue, tão frágil, pouco capaz de se manter no tempo. Tampouco reivindicam para si o lugar de ingênuas. Para as melancólicas, ser ingênua é quase um defeito de caráter. São vítimas porque a condição humana, a realidade brutal da consciência da castração não permite, segundo elas, um outro lugar que não esse. Mas não se pretendem as únicas vítimas, para elas todas nós somos vítimas. Na relação transferencial, o analista é testemunha do esforço delas em se resgatarem, se constituírem narcisicamente, sob o olhar de alguém. Ser uma outra é ser qualquer um, não há individualidade, singularidade, essa outra é um universal, uma bula para viver, não mais que isso. O que elas buscam no espaço analítico é um recuperar o si mesmo para poder abrir mão desta outra. 


\section{Referências}

Abraham, N. e Torok, M. A casca e o núcleo. São Paulo: Escuta, 1995.

Freud, S. (1896). La etiología de la histeria. In: Obras completas Sigmund Freud. Buenos Aires: Amorrortu, 1993. v. III.

(1908). Las fantasías histéricas y su relación con la bisexualidad. In: O.C. Op. cit. v. IX. Tradução da Edição Eletrônica das Obras Completas de Sigmund Freud. Rio de Janeiro: Imago.

(1914). Contribución a la historia del movimiento psicoanalítico. In: O.C. Op. cit. v. XIV. Tradução da Edição Eletrônica das Obras Completas de Sigmund Freud. Rio de Janeiro: Imago.

(1921). Psicologia de las masas y análisis del yo. In: O.C. Op. cit. v. XVIII. Tradução da Edição Eletrônica das Obras Completas de Sigmund Freud. Rio de Janeiro: Imago.

e FuIEss, W. Correspondência completa (1887-1904). Rio de Janeiro: Imago, 1986, carta de 21/9/1897. Tradução da Edição Eletrônica das Obras Completas de Sigmund Freud. Rio de Janeiro: Imago.

KenL, Maria Rita. Deslocamentos do feminino. Rio de Janeiro: Imago, 1998.

PinheIro, Teresa. Ferenczi, do grito à palavra. Rio de Janeiro: Jorge Zahar/UFRJ, 1995.

Algumas considerações sobre o narcisismo, as instâncias ideais e a melancolia.

Cadernos de Psicanálise, SPCRJ, v. 12, n. 15, p. 20-8, nov/1995a.

Num tempo sem ilusão. IV Fórum brasileiro de Psicanálise - A cultura da ilusão. Rio de Janeiro, 1997. p. 41-5.

A castração: do interdito ao desamparo. Saúde, Sexo e Educação - Edição especial: II Fórum de Psicanálise. Rio de Janeiro, n. 12, 1997a. p. 41-4.

Algumas questões da metapsicologia freudiana. Psicologia Clínica, n. 12, p. 55-64, 2000.

O texto imagético: parnasianismo e experiência analítica. In: Lo BIANCo, A.C. (Org.). Formações teóricas da clínica. Rio de Janeiro: Contra Capa, 2001. p. 57-72.

Escuta psicanalítica e novas demandas clínicas. Revista Psychê, n. 9, p. 16776, jun./ 2002.

; Jordão, Alexandre; e Holanda Martins, Karla. A certeza de si e o ato de perdoar. Cadernos de Psicanálise, v. 14, n. 17, p. 160-75, 1998.

Verztman, Julio Sérgio. O observador do mundo: a noção de clivagem em Ferenczi. Revista Ágora, v. V, n. 1, p. 59-78, jan.-jun./2002. 


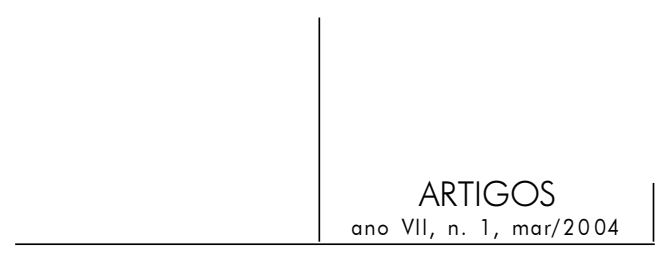

Resumos

Este trabajo pretende comparar la histeria con el falso-self a partir del proyecto de "ser una otra" presente en ambas patologías. El proyecto de " tornarse una otra", en la histeria, apunta para personajes que están necesariamente presentes en este modelo fantasmático: la víctima y el villano. La noción de "ser una otra", en el falsoself, se presenta como la única forma posible de estar en el mundo, donde no hay lugar para la ilusión.

Palabras clave: Histeria, falso-self, fantasía, ilusión, melancolía

Ce travail a pour but d'établir une comparaison entre l'hystérie et le faux-self par le biais du projet d' "être une autre", présent dans les deux pathologies. Le projet de "devenir une autre" dans l'hystérie montre les personnages qui sont nécessairement présents dans ce modèle fantasmatique: la victime et le bourreau. La notion "d'être une autre” dans le faux-self se présente comme le seul moyen possible d'être au monde, où l'illusion n'a pas de place.

Mots clés: Hystérie, faux-self, fantasme, illusion, mélancolie

This article consists of a comparison between hysteria and false self that begins with a project of "being someone else," present in both pathological forms. The project of "becoming someone else" in hysteria refers to fictional characters that are necessarily present in this type of fantasy: the victim and the villain. The notion of "being someone else," a false self, arises as the only possible way of existing in the world, where there is no place for illusion.

Key words: Hysteria, false self, fantasy, illusion, melancholia

Versão inicial recebida em setembro de 2003

Versão revisada recebida em outubro de 2003 